\title{
Diagnóstico da tripanossomíase bovina por diferentes técnicas laboratoriais
}

Pedro Henrique Vieira Germano;,Alex André da Silva, Gertrud Elisa Campos Edler, Luis Oliveira Lopes

Centro Universitário de Patos de Minas (UNIPAM), Patos de Minas, MG, Brasil

*Autor correspondente

e-mail: pedro.vieira11@yahoo.com.br

\section{Resumo}

A tripanossomíase bovina, causada por um protozoário do gênero Trypanosoma, é uma doença de ocorrência mundial, gerando grandes perdas econômicas devido à queda no desempenho produtivo e, muitas vezes, morte dos animais. Foi registrada pela primeira vez no Brasil em 1972, no Pará, infectando búfalos. Recentemente, tem sido reportada em várias regiões de Minas Gerais. 0 objetivo do trabalho foi realizar um comparativo entre três técnicas de diagnóstico parasitológicas e uma sorológica para tripanossomíase bovina na região de Patos de Minas, Minas Gerais. Durante um estudo soroepidemiológico de tripanossomíase, foram analisadas 30 amostras sanguíneas de bovinos, sendo 10 animais da raça Nelore e 20 animais em lactação da raça Holandesa e Girolando, com diferentes graus de sangue, sendo primíparas e/ou plurípara, em propriedades rurais do município de Patos de Minas. 0 estudo parasitológico foi conduzido no Laboratório de Patologia Clínica do Centro Clínico Veterinário (CCV) do Centro Universitário de Patos de Minas, empregando as seguintes técnicas: Gota espessa, Woo e Buffy Coat. Já a técnica sorológica utilizada foi a reação de imunofluorescência indireta (RIFI), realizada na Universidade Federal de Minas Gerais. Das 30 amostras estudadas, nove (30\%) apresentaram resultados positivos na técnica de Woo, na qual foi possível visualizar as formas tripomastigotas. Porém nas outras técnicas parasitológicas (Gota Espessa e Buffy Coat) não se encontrou positividade, sendo isso atribuído à baixa parasitemia dos animais infectados. 0 teste de Woo é o mais indicado a campo, sendo de fácil execução e rapidez no reconhecimento dos trypanosomas, principalmente quando a parasitemia da amostra é baixa, pois o método apresenta maior sensibilidade entre as técnicas parasitológicas da doença. Contudo, a desvantagem da técnica é que as amostras devem ser avaliadas rapidamente após a colheita do sangue ( 2 - 4 horas), caso contrário, o número de tripomastigotas reduzem devido à diminuição de produtos metabólicos e lise das células, fazendo com que o teste perca sua sensibilidade e gerando um falso negativo. Já na técnica sorológica RIFI, sete (24\%) 
dos animais apresentaram-se positivos, ou seja, possuíam anticorpos anti-T. vivax; os títulos variaram de 80 a 640. Métodos de diagnósticos como a RIFI podem comprovar se os animais negativos nos exames parasitológicos eram realmente negativos. Na fase crônica da doença, as técnicas parasitológicas demostram baixa sensibilidade, devido à parasitemia baixa, e flutuante, sendo o estudo sorológico importante na complementação dos exames parasitológicos, tornando-se importante a realização de métodos sorológicos como a RIFI, considerada padrão ouro para o confirmatório de tripanossomíases. Pode-se concluir que a técnica de Woo é a mais indicada para diagnóstico da doença em fase aguda e que a técnica da RIFI é mais sensível para detecção de tripanossomíase em fase crônica, assim, nenhum dos métodos deve ser empregado de forma isolada. 